\title{
Association between Previous Experience of Strength Training under Appropriate Supervision and Knowledge of Squats among University Students Who Exercise Regularly*
}

Kazushige Oshita $^{1}$, Goichi Hagiwara ${ }^{2}$, Takafumi Monma ${ }^{3,4}$, Tempei Tsuno ${ }^{5}$, Kazushi Koizumi ${ }^{6}$, Yasuhumi Oyama $^{7}$, Kyohei Yamaguchi', Tomoki Tashiro' ${ }^{1}$ and Kyotaro Funatsu' ${ }^{1}$

${ }^{1}$ Department of Sport Science, Kyushu Kyoritsu University, 1-8, Jiyugaoka, Yahatanishi, Kitakyushu, Fukuoka, 807-8585 Japan oshita@kyukyo-u.ac.jp

${ }^{2}$ Department of Sports Humanities and Applied Social Science, National Institute of Fitness and Sports in Kanoya, 1 Shiromizu-cho, Kanoya, Kagoshima, 891-2393 Japan

${ }^{3}$ Research Fellow of Japan Society for the Promotion of Science, Japan Society for the Promotion of Science, 5-3-1 Kojimachi, Chiyoda-ku, Tokyo 102-0083, Japan

${ }^{4}$ Faculty of Health and Sport Sciences, University of Tsukuba, 1-1-1 Tennodai, Tsukuba, Ibaraki 305-8577, Japan

${ }^{5}$ Graduate School of Physical Education, National Institute of Fitness and Sports in Kanoya, 1 Shiromizu-cho, Kanoya, Kagoshima, 891-2393 Japan

${ }^{6}$ Department of Lifelong Sports and Recreation, Nippon Sport Science University, 1221-1 Kamoshida-cho, Aoba, Yokohama, Kanagawa 227-0033 Japan

${ }^{7}$ Faculty of Sports and Health Science, Fukuoka University, 8-19-1 Nanakuma, Jonan, Fukuoka 814-0180 Japan

*Original article published in Japan J. Phys. Educ. Hlth. Sport Sci. 60: 539-550, 2015 (in Japanese)

[Received February 15, 2016; Accepted June 3, 2016; Published online June 28, 2016]

The aim of the present study was to investigate the effect of experience or inexperience with weight-training under appropriate supervision on the knowledge of squatting exercises among university students. A questionnaire-based survey was conducted among university students who exercise regularly (30 or more min per day, 2 or more days per week, and maintaining this for more than 1 year) to clarify the relationships between their experience of weight-training under appropriate supervision, knowledge of squatting exercises, and the frequency with which they perform squatting exercises $(n=309)$. More than half of the students who exercised regularly had never experienced weight-training under appropriate supervision. Approximately $50 \%$ of the participants performed squats periodically, even if they did not have any experience with weight-training under appropriate supervision. The participants who lacked experience with weight-training under supervision had made significantly fewer attempts to consciously train their gluteal and knee flexor muscles during squatting exercises than those who had experienced weight-training under supervision. In fact, approximately $50 \%$ of the former did not consciously train their gluteal muscles during squatting exercises at all. These results suggest that although the students performed squatting exercises periodically, those who had never experienced weight-training under supervision may not have properly understood the squatting method. Therefore, to enhance the benefits of training, people should be shown the correct method to perform training exercises and given appropriate supervision.

Keywords: Strength training, Exercise instructor, Hip extensor muscles, Knee extensor muscles

\section{Introduction}

Strength-training, which helps in the maintenance and development of muscle strength and mass, does not only contribute to improved performance in competitive sports but also helps people maintain and improve their overall health. As such, it has attracted interests globally, Japan included. For 
instance, although the Worldwide Survey of Fitness Trends ${ }^{* 1}$ acknowledged core training, boot camps, and yoga as fitness trends, strength-training has always been given the top priority (Thompson, 2011, $2012,2013,2014)$. The survey results also stated that the maintenance and enhancement of muscle function through weight-training concerns everyone, irrespective of age and sex (Thompson, 2013). Squatting exercises, for example, are the most typical (Ishii, 2009) and common (Chiu and Burkhardt, 2011) exercise within the set of dynamic resistance training (in this paper, squats refer to back squats or basic bodyweight squats). Although squats are usually associated with jumping or sprinting performances in athletes (McBride et al., 2009; Wisloff et al., 2004), they have been introduced by health and fitness organizations as a typical weight-training exercise (Ishii, 2009). In addition, they have recently been recommended for the prevention of "locomotive syndrome (Nakamura, 2008)," and as an exercise to strengthen the lower body muscles and improve balance (Nakamura, 2012).

Important muscles recruited during squatting exercises are the gluteus maximus, semimembranosus, semitendinosus, biceps femoris, vastus lateralis, intermediate vastus, vastus medialis, rectus femoris (Earle and Baechle, 2010), and erector spinae (Aruga, 2009). In short, squatting exercises train the hip as well as the knee extensors (Earle and Baechle, 2010; Aruga, 2009). It is also an exercise of multijoint movements, recruiting several muscle groups. Therefore, it provides a higher variety and freedom of movement, compared to exercises that incorporate only single-joint movements. The activity of recruited muscle groups during squatting exercises varies according to the width of feet stance (McCaw and Melrose, 1999), angles of the knees and hips (Escamilla et al., 1998; Fry et al., 2003; Manabe et al., 2004), squatting depth (Caterisano et al., 2002), and weight load (Manabe et al., 2003). In addition, several reports suggest that squats are difficult to perform if the flexibility of one's lower body (including the pelvic girdle) is less, or if one's range of motion is restricted (Fukui, 2006; Miura and Oda, 2001; Ogasawara, 2013). For these reasons, there have been various discussions regarding the proper technique of performing squats; some researchers have pointed out that it is a difficult exercise to perform correctly, even among athletes (Chiu, 2009). In fact, a study that examined young people's recogni- tion of trained body parts while doing squats reported that most of them did not recognize the gluteal as a trained area (Oshita et al., 2014). This indicates the likelihood of squats being performed incorrectly, like a lower torque movement of the hip joints.

Strength-training performed wrongly not only leads to the loss of its beneficial effects but also increases the risk of injuries. Therefore, strength and conditioning organization advocates performing squats under appropriate supervision (National Strength \& Conditioning Association, 1991). In fact, this should apply to all sports activities, in order to ensure that they are "safe, correct, and fun" (Japan Sports Association, 2014). However, this is not the case with many exercises. For example, a survey among athletic club faculties of junior high schools and high schools across the country reported that $40-45 \%$ of these faculties were not in charge of physical education and did not have experience in the activities they were responsible for (Japan Sports Association, 2014). Moreover, in a survey of a particular region, it was reported that $69 \%$ of the athletic club faculty did not possess teaching licenses for physical education or certified qualifications from the Japan Sports Association (Teraoka and Matsumoto, 2015). These reports suggest that most strength-training and sports activities are likely carried out without appropriate supervision.

Unfortunately, unlike competitive sports, there are no sporting regulations or rules for strengthtraining; instead, various exercising methods are featured in books, television programs, and so on. Therefore, an individual can strength-train even without prior supervision and knowledge of these exercises. However, if strength-training is improved with appropriate supervision, this could increase the appeal of a professional instructor. Furthermore, it may strengthen evidence of this importance as recommended by strength-training organizations. The aim of this study was to investigate the effect of experience or inexperience with weight-training under appropriate supervision on the frequency of performing squatting exercises (the most common (Chiu and Burkhardt, 2011) and typical (Ishii, 2009) exercise in strength-training) and the knowledge of squatting exercises among university students. 


\section{Method}

\subsection{Participants}

Our participants comprised 494 men and women from national universities, private universities, and national colleges of technology (where a fourth-year college student is the equivalent of a first-year university student). A questionnaire-based survey was conducted from October to December 2014 using the collective survey method. Participants were verbally informed beforehand that the questionnaire answers would be anonymous and used only for research purposes. They were also informed that while obtained data would be published after being statistically processed such that individuals cannot be personally identified, some diagrams may be published as they are. The survey was conducted only if these terms were accepted. This study was approved by the ethics committee of Kyushu Kyoritsu University.

\subsection{Participants for analysis}

The results of the questionnaire excluded 171 participants who, according to the National Health and Nutrition Survey conducted by the Ministry of Health, Labor and Welfare (2014), did not exercise regularly, have never performed squats, or did not know about squats. It further excluded 14 participants whose answers were incomplete. This left 309 participants (264 men and 45 women) for the analysis. This study limited the participants of analysis to those who exercised regularly (30 minutes or more per day, 2 or more days a week, and maintaining this for more than 1 year), considering reports that regular exercise habits affect one's recognition of trained body parts (Oshita et al., 2014). Furthermore, we postulate that participants without regular exercise habits are less likely to have received supervised weight-training.

Among the participants, 22 did not participate in any sport, while the remaining 272 did. The breakdown according to specific sports is as follows (numbers in brackets indicates the number of participants): soccer (40), baseball or softball (37), basketball (34), swimming (30), track and field (28), Kendo (23), lifeguarding (14), rugby or American football (14), volleyball (9), futsal (9), gymnastics/acrobatics/dancing/cheerleading (9), handball
(6), tennis (5), badminton (5), snow sports such as skiing or snowboarding (4), under-water sports including diving or surfing (4), double Dutch (3), rowing (3), triathlon (2), combative sports (2), golf (1), mountaineering (1), hockey (1), cycling (1), lacrosse (1), and ultimate Frisbee (1).

\subsection{Questionnaire survey}

The questionnaire-based survey was conducted under five headings: participants' physical activity status, competitive records, experience with weighttraining under appropriate supervision, frequency of performing squats, and perceived body parts trained by squats.

Question 1, relating to physical activity, was "Do you exercise more than twice a week (for at least 30 minutes at a time)?" with the three answer options, "No, I do not," "Yes, for less than a year," and "Yes, for more than a year."

Question 2, relating to competitive records, was "Please select the appropriate option in relation to your competitive records," with the four answer options, "National competition finalist or higher," "National competition participant," "Regional competition participant," and "Others (including no experience in competitive sports)."

Question 3, relating to the experience with weighttraining under appropriate supervision, was "Have you weight-trained under appropriate supervision?" with two answer options: "Yes" and "No." Those who answered "No" were further asked whether "they exercised without any reference" or whether "they exercised while watching videos" and so on. Additionally, those who answered "Yes" were asked whether they received guidance from weighttrainers, sports experts, or individuals who were of neither these two professions (e.g., seniors, friends, etc.).

Since squatting exercises in this study are classified into sissy squats, front squats, and others, question 4 (relating to the frequency of performing squats) was presented along with a picture of a back squat from the manual of the National Strength \& Conditioning Association (Figure 1) (Earle and Baechle, 2010). The question was "Have you performed a squat as shown in the picture?" with the following 6 answer options: "Almost everyday," "Several times a week," "Several times a month," "At least once," "Never," and "I do not know about 
Have you performed a squat as shown in the picture?

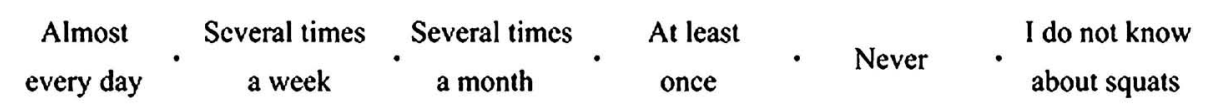
in right figure)
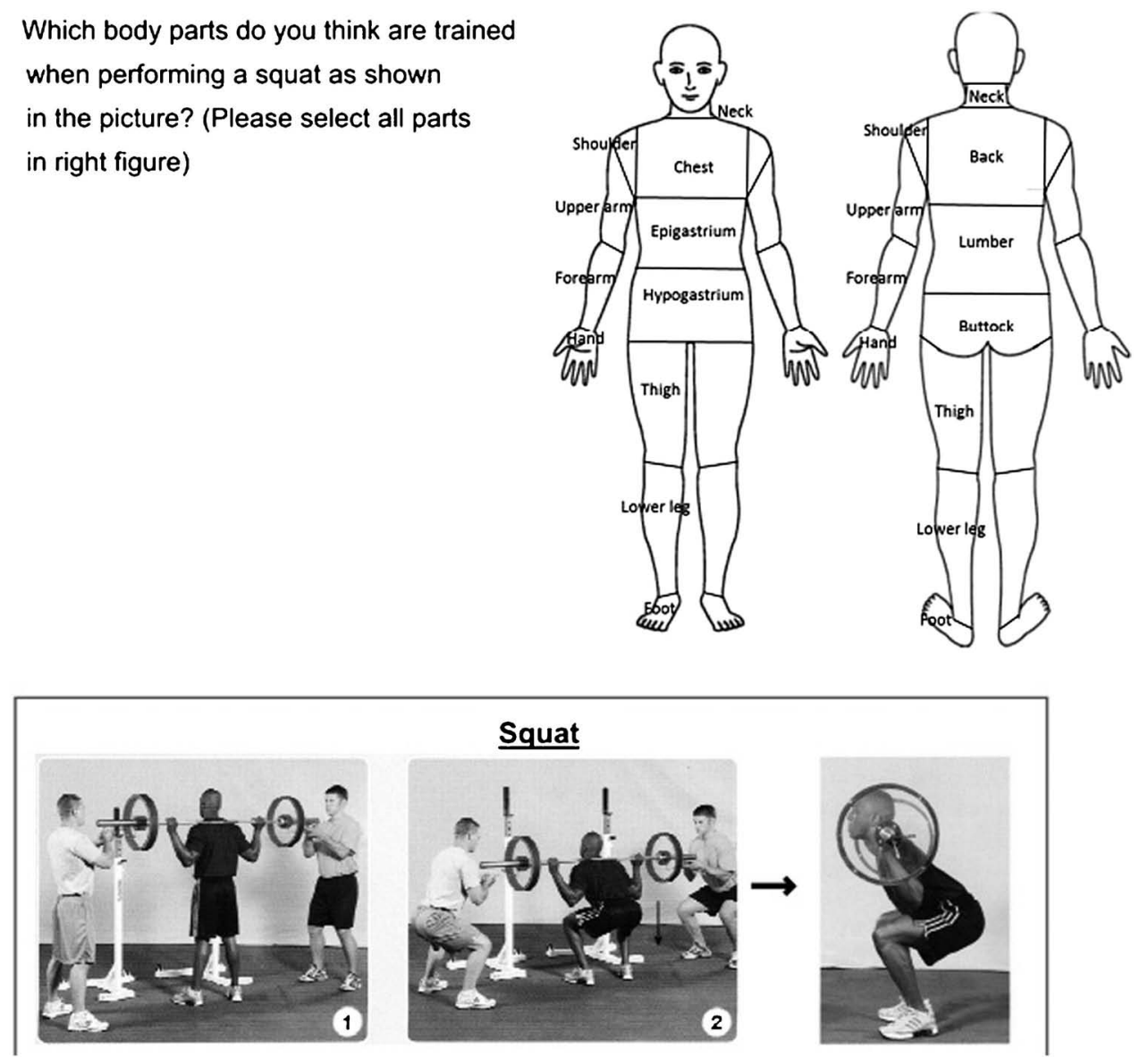

Figure 1 Questionnaire about the perceived body parts trained by squats

A picture of a back squat (source: the manual of the National Strength \& Conditioning Association (Earle and Baechle, 2010))

squats".

Question 5, regarding the recognition of body parts trained by squats, was "Which body parts do you think are trained when performing a squat, as shown in the picture?"' To answer, participants were shown a diagram depicting the anterior and posterior views of the body. Body parts such as the neck, chest, epigastrium, hypogastrium, shoulders, upper arms, forearms, hands, thighs, lower legs, feet, back, lumbar, and buttocks were marked off (Figure 1). Participants could select multiple options in their answers.

\subsection{Data analysis}

When aggregating the results of the questionnaire analysis, the percentages of answer options for each question were compared using the chi-square goodness of fit test. This was followed by multiple analyses using Ryan's method.

Based on their answers, participants were categorized into those who have experienced weight-training under appropriate supervision (EXP-group) and those without experience (NOE-group). The latter also included those who were supervised by nonprofessionals. To examine the relationship between competitive records, frequency of performing squats and supervised weight-training, a chi-square test was 
performed. For perceived body parts trained by squats, the percentage of participants who did or did not recognize training of different body parts was compared between the EXP- and NOE-group using the chi-square test. We also conducted Fisher's exact test for cases where the expected frequency was below 5 .

Using statistical analysis software (J-STAT version 12.5 and js-STAR version 2.0.6), the established level of statistical significance is less than $5 \%$. We further calculated the $V$ values using Cramer's method, and established the effect size as small for $V$ less than 0.1 , large for $V$ greater than 0.5 , and moderate for other cases.

\section{Results}

The aggregated results of the questionnaire are shown in Table 1. Among the participants, 12 were national competition finalists or higher, 67 were national competition participants or higher, and 149 were regional competition participants. The remaining 81 did not fall into any of these categories $(P<$ $0.01)$. With regards to their experience with supervised weight-training (question 3), 146 participants had experience with professional weight-trainers or sports experts, 110 did not, while 53 had experience with individuals who were non-experts $(P<0.01)$. These results indicate that even among university students who exercised regularly, a majority of them have never experienced supervised weight-training. As for the frequency of performing squats (question 4), 3 participants performed squats almost everyday, 85 several times a week, 51 several times a month, and 170 at least once $(P<0.01)$. This indicates that approximately half of university students with regular exercise habits perform squats periodically (several times a month).

Figures 2 and 3 show the aggregated results of each question by categorizing the EXP-group and the NOE-group accordingly. Among the EXPgroup, $6.9 \%$ were national competition finalists or higher, $22.6 \%$ were national competition participants or higher, $47.9 \%$ were regional competition participants, and $22.6 \%$ did not fit into these categories. In the NOE-group, the percentages were $1.2 \%$, $20.9 \%, 48.5 \%$, and $29.4 \%$, respectively. With no significant difference being observed, the effect size was moderate $(V=0.16)$ (Figure 2). This suggests that there is no observable association between one's experience with supervised weight-training and one's competitive record.

With regards to the association between one's experience in supervised weight-training and frequency of performing squats (question 4), the EXP-group consisted of $1.4 \%$ who performed squats almost everyday, $31.5 \%$ several times a week, $17.8 \%$ several times a month, and $49.3 \%$ at least once; on the other hand, the NOE-group had $0.6 \%, 23.9 \%, 15.3$ $\%$, and $60.1 \%$, respectively. Again, no significant difference was observed here and the effect size was moderate $(V=0.11)$ (Figure 3). This indicates that prior supervised weight-training had no influence on the frequency of performing squats. In fact, approximately half of the participants performed squats periodically, even if they did not have any experience with weight-training under appropriate supervision.

Table 1 Aggregated results of the questionnaire

\begin{tabular}{|c|c|c|c|c|}
\hline (Question 2) Competitive records & $\begin{array}{l}\text { (1) National com- } \\
\text { petition finalist } \\
\text { or higher }\end{array}$ & $\begin{array}{l}\text { (2) National com- } \\
\text { petition partici- } \\
\text { pant or higher }\end{array}$ & $\begin{array}{l}\text { (3) Regional com- } \\
\text { petition partici- } \\
\text { pant or higher }\end{array}$ & (4) Other \\
\hline $\begin{array}{r}\chi^{2}=123.30, P<0.01 \\
(1)<(2),(1)<(3),(1)<(4),(2)<(3),(3)>\text { (4); } P<0.01\end{array}$ & $\begin{array}{c}3.9 \% \\
(\mathrm{n}=12)\end{array}$ & $\begin{array}{l}21.7 \% \\
(\mathrm{n}=67)\end{array}$ & $\begin{array}{c}48.2 \% \\
(n=149)\end{array}$ & $\begin{array}{l}26.2 \% \\
(\mathrm{n}=81)\end{array}$ \\
\hline $\begin{array}{l}\text { (Question 3) Experience with undergoing instruction for } \\
\text { strength training }\end{array}$ & (1) None & (2) From experts & $\begin{array}{l}\text { (3) From } \\
\text { non-experts }\end{array}$ & \\
\hline $\begin{array}{r}\chi^{2}=42.70, P<0.01 \\
\text { (1) }<\text { (2); } P<0.05,(1)>(3),(2)>(3) ; P<0.01\end{array}$ & $\begin{array}{l}35.6 \% \\
(n=110)\end{array}$ & $\begin{array}{c}47.2 \% \\
(n=146)\end{array}$ & $\begin{array}{l}17.2 \% \\
(\mathrm{n}=53)\end{array}$ & \\
\hline (Question 4) Frequency of performing squats & $\begin{array}{l}\text { (1) Almost } \\
\text { everyday }\end{array}$ & $\begin{array}{l}\text { (2) Several times } \\
\text { a week }\end{array}$ & $\begin{array}{l}\text { (3) Several times } \\
\text { a month }\end{array}$ & $\begin{array}{l}\text { (4) At least } \\
\text { once }\end{array}$ \\
\hline $\begin{array}{r}\chi^{2}=192.42, P<0.01 \\
\text { (1) < (2), (1)<(3), (1)< (4), (2)> (3), (2)<(4), (3)< (4); } P<0.01\end{array}$ & $\begin{array}{l}1.0 \% \\
(\mathrm{n}=3)\end{array}$ & $\begin{array}{l}27.5 \% \\
(n=85)\end{array}$ & $\begin{array}{l}16.5 \% \\
(n=51)\end{array}$ & $\begin{array}{c}55.0 \% \\
(n=170)\end{array}$ \\
\hline
\end{tabular}




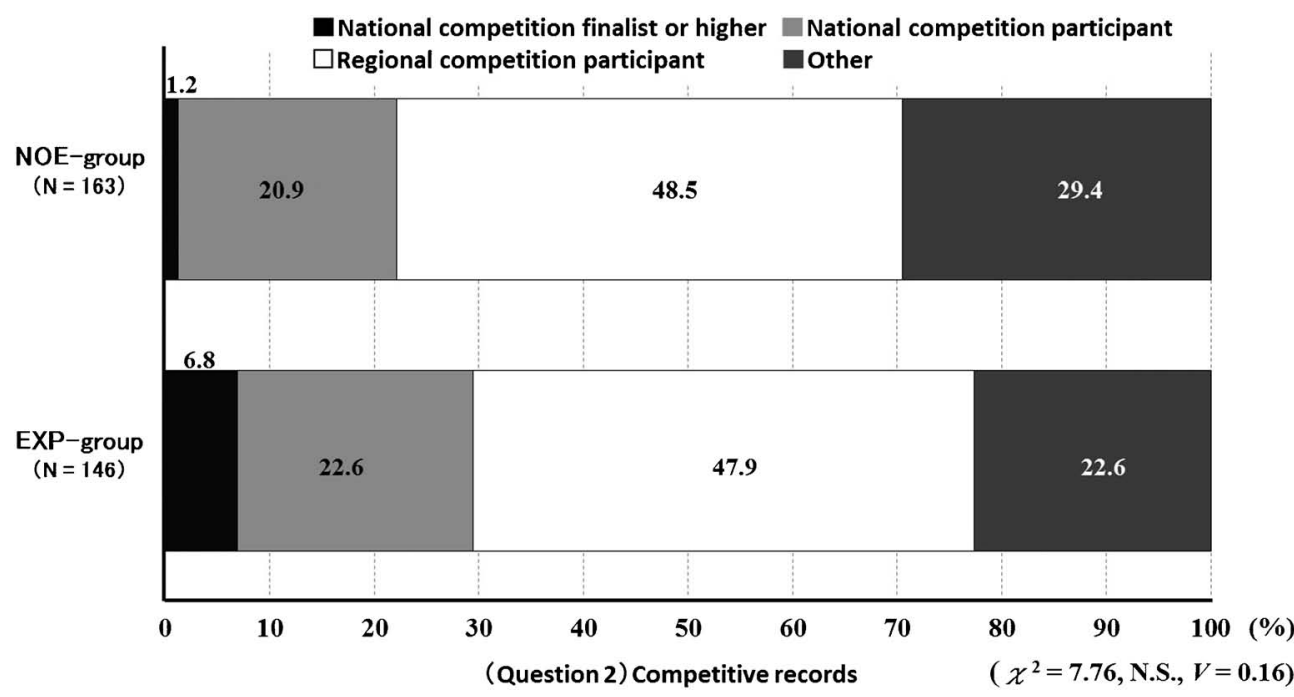

Figure 2 Competitive records (question 2) among the EXP- and NOE-group EXP-group: Participants who have experience with weight-training under appropriate supervision NOE-group: Participants who have no experience with weight-training under appropriate supervision and/or who have received supervision with non-professionals

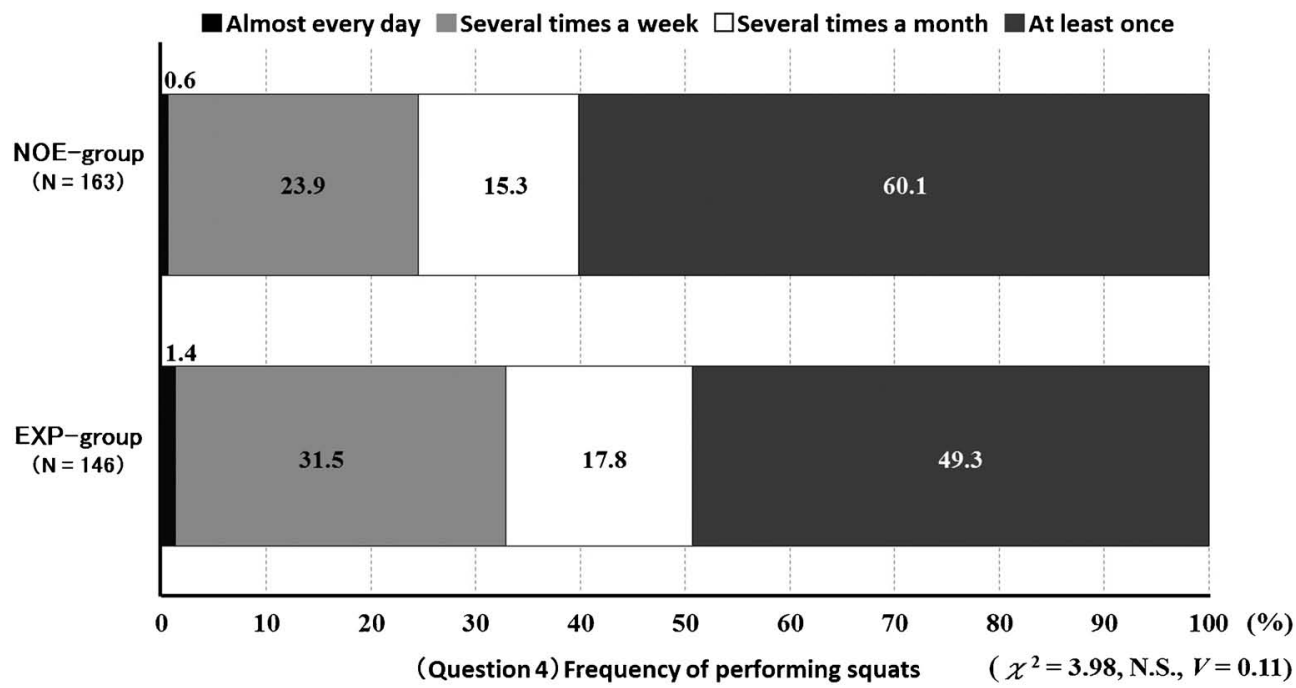

Figure 3 Frequency of performing squats (question 4) among the EXP- and NOE-group EXP-group: Participants who have experience with weight-training under appropriate supervision NOE-group: Participants who have no experience with weight-training under appropriate supervision and/or who have received supervision with non-professionals

Figure 4 shows the aggregated results for the association between experience with supervised weighttraining and recognition of trained body parts (question 5). In both groups, most participants (90\%) perceived the anterior thighs as trained areas. The corresponding percentages for the other parts were $80-90 \%$ for the posterior thighs, $50-70 \%$ for the gluteal muscles, $40 \%$ for the lumbar and posterior lower legs, $30 \%$ for the anterior lower legs, $20-30 \%$ for the hypogastrium and back, $10 \%$ for the epigastrium and shoulders, $5-10 \%$ for the feet and arms,
$2-7 \%$ for the posterior neck, and less than 5\% each for the chest, forearms, hands and anterior neck. Among these, $92 \%$ of the EXP-group marked the posterior thighs, compared to $83 \%$ of the NOEgroup; similarly, $69 \%$ of the EXP-group marked the gluteal region, compared to $56 \%$ of the NOE-group. Interestingly, only $2 \%$ of the EXP-group marked the posterior neck, compared to $7 \%$ of NOE-group. Significant differences were observed between the groups $(P<0.05)$, and the effect size was moderate $(V=0.12-0.14)$ in these parts. For other body parts, 


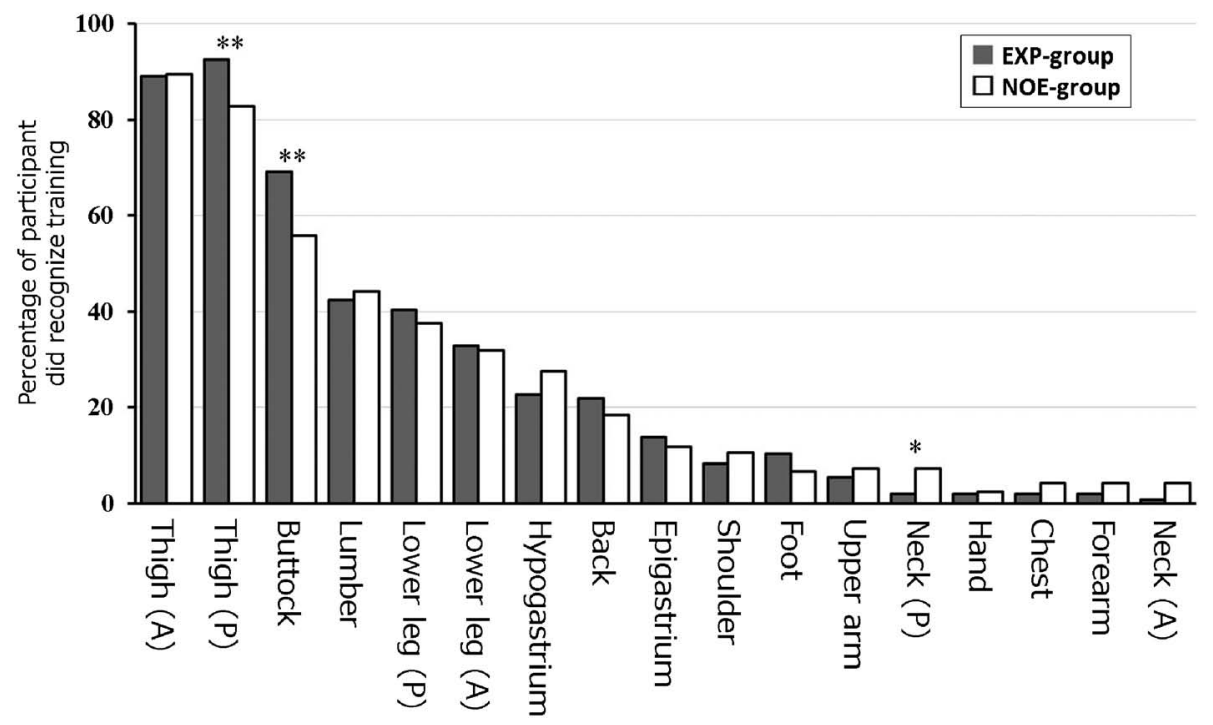

Figure 4 The percentage of participants who did recognize training in each body parts during squats (question 5) among the EXP- and NOE-group

EXP-group: Participants who have experience with weight-training under appropriate supervision NO-group: Participants who have no experience with weight-training under appropriate supervision and/or who have received supervision with non-professionals

A: Anterior

P: Posterior

*; $P<0.05$

$* * ; P<0.01$
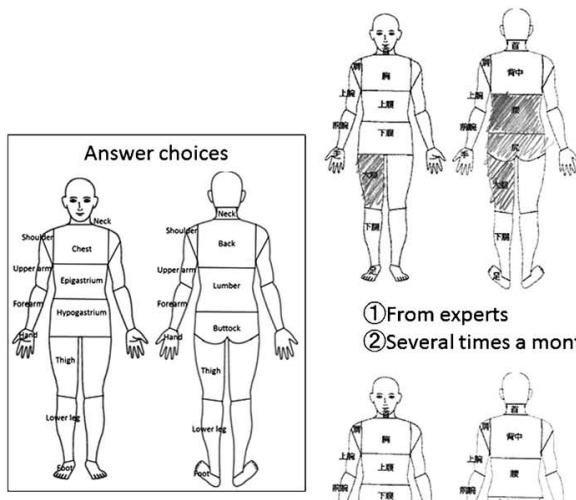

(1)From experts

(2) Several times a month

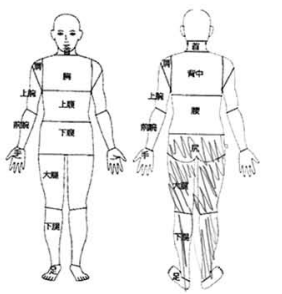

(1) with watching videos (2) Several times a week

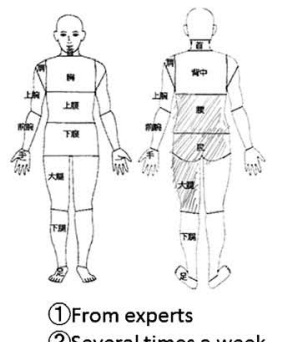

(2)Several times a week

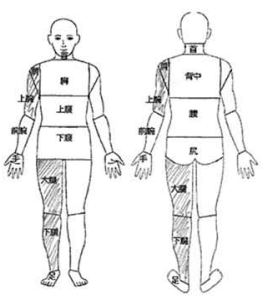

(1) without any instruction (2) At least once

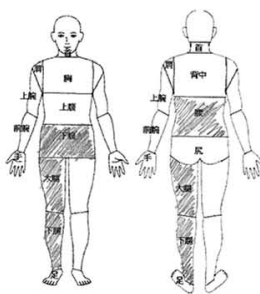

(1)From non-experts (2)At least once

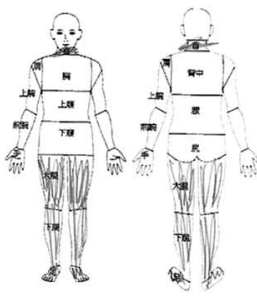

(1) without any instruction (2) Several times a week

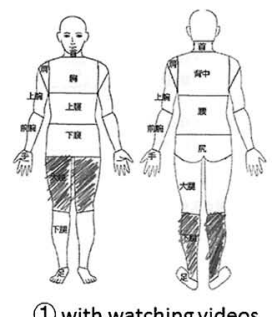

(2) At least once

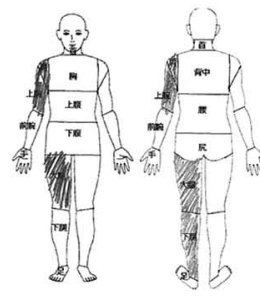

(1)From experts

(2)Several times a week

Figure 5 Example of answers regarding perceived body parts trained during squats (question 5)

(1)Experience with appropriate supervision for weight-training

(2)Frequency of doing squats

difference between the groups was not statically significant, and the effect size was small $(V<0.1)$. These results suggest that although more than $80 \%$ of participants recognized that thighs are being trained, the recognition of the posterior thighs was higher among participants who had supervised weight-training; similarly, about $70 \%$ of partici- pants who had supervised weight-training recognized the training of the gluteal region, compared to only half of participants without appropriate supervision. Interestingly, the posterior neck, although infrequently marked, was recognized by more participants in the NOE-group than the EXP-group. An example of these answers is shown in Figure 5. 


\section{Discussion}

This study revealed that 1) even among university students who exercised regularly, more than half never received supervised weight-training; 2) the experience of appropriate supervision had no effect on the frequency of performing squats, and; 3 ) those without prior supervised training have less perception of the training of hip extensor muscles during squats.

Strength-training is important for everyone, irrespective of their age and sex. The presence of an appropriate supervisor is equally significant. In their annual prediction for top fitness trends, the Worldwide Survey of Fitness Trends*1 listed certified and experienced fitness professionals in third place in their 2014 and 2013 surveys (Thompson, 2013, 2014); in 2012 and 2011, these experts were placed first (Thompson, 2011, 2012). This shows that there is a worldwide demand not only for fitness instructors, but also for those with a high degree of knowledge and experience in this field. However, the results of the present study showed that even among university students who exercised regularly, more than half have never received appropriate supervision. Using squats as a representative strength-training exercise, this study found that the frequency of performing squats was not dependent on prior supervised training, and that approximately half of the participants performed squats periodically, regardless of their experience. Although performing squats with supervision is important as it enhances performance and prevents injuries (National Strength \& Conditioning Association, 1991), our results showed that strength-training is often practiced in the absence of appropriate supervision.

With regards to the recognition of trained body parts, although many participants identified thighs (both anterior and posterior) and gluteal muscles, a significant difference between the EXP- and NOEgroup was observed for the gluteal region and posterior thighs. When performing squats, it is recommended that the knees are positioned exactly above the feet (Aruga, 2009; Earle and Baechle, 2010), and that the shins are kept straight (Fry et al., 2003) while descending and ascending; in other words, the exercise is performed akin to "sitting on a chair (Chiu, 2009)." Performed this way, squats can build up the knee- and hip extensor muscles, and reduce the risk of injuring lower limb joints
(Manabe et al., 2004). This effectively strengthens the muscles of the lower body. For squats with $60-70 \%$ repetition maximum resistance, more than $40 \%$ maximum voluntary contraction activation can be seen in the rectus femoris, vastus lateralis, and intermediate vastus muscles during the descending and ascending phases (Escamilla et al., 1998; Manabe et al., 2004). Although the activity of the gluteus maximus and biceps femoris is almost the same compared to that of the rectus femoris and vastus lateralis during the ascending phase, the activity is lowered during the descending phase (Escamilla et al., 1998; Manabe et al., 2004). These results suggest that the perception of training the gluteal region and posterior thighs is lower than that of the anterior thighs, where there is greater activity during both the ascent and descent. However, squats is an exercise to train hip extensor and knee extensor muscles. Therefore, based on the principle of consciousness (Kouda, 1994), squats should be performed with a perception to train hip extensor muscles as well as knee extensor muscles. On the other hand, when performing squats, the same level of activity is observed in the erector spinae muscles as well as in the rectus femoris and vastus lateralis muscles (Manabe et al., 2004), in order to maintain the posture of the trunk. However, less than half the number of participants marked the lumbar area (which contains the erector spinae muscles) in their answers, irrespective of their experience with supervised training. This may have been secondary to less prioritization in maintaining posture when performing squats. It is therefore advisable to practice any form of exercise only after one has a clear understanding on how to consciously perform it.

There is also the possibility that squats are not performed correctly when there is less perceived training of the hip extensors (i.e., the posterior thighs and gluteal muscles). For instance, a squat is performed by keeping the upper body upright and the act of bringing the knee joints forward without flexing the hips causes greater torque on the knee joints compared to the hip joints (Fry et al., 2003). During this act, the activity of the rectus femoris muscle significantly increases while that of the femoral biceps significantly reduces (Manabe et al., 2004). In addition, limitations in squat movements may arise depending on the flexibility of one's lower body muscles, including the pelvic girdle (Fukui, 2006; Miura and Oda, 2001, Ogasawara, 2013). If a 
person performs squats with a shallow angle motion, the activity of the gluteus maximus is reduced compared to that of the thigh muscles (vastus lateralis, vastus medialis and biceps femoris) (Caterisano et al., 2002). Since the present study only investigated the body parts trained by squats and did not examine the actual movements, these suggestions are mere conjectures. However, reports have stated that when squats are perceived to exercise only the femoral quadriceps, there is a tendency to perform greater knee joint torque squats (Ogasawara, 2013). Therefore, participants in the NOE-group might have performed higher number of knee joint torque squats, leading to lowered levels of perceived training of the gluteals and posterior thighs. In the case of greater knee joint torque squats, the load on the knee joints increases the more the knees are brought forward (Ishii, 2009). In order to prevent chronic knee problems, it is recommended to not position the knees beyond the front of the toes (Ishii, 2009). While a slight forward-position may train many lower limb muscles (Fry et al., 2003), excess is a common error (Aruga, 2009). The results of this study suggest the possibility that exercises may be performed wrongly due to differences in perceived trained body parts as a result of one's experience with supervised training. It also stresses the importance of appropriate supervision in preventing injuries during exercise.

As shown in the example in Figure 5, some participants perceived training in their arms, shoulders, and/or neck while doing squats. Although few participants marked the posterior neck, more NOEgroup participants marked this area compared to the EXP-group. There is a possibility that the arms, shoulders, and neck were marked in the answers as a result of the depiction of a back squat (with a shaft being carried on the shoulders) in the questionnaire (Figure 1). Even among participants who exercised regularly, some answered the lower relation parts during actual movements of the squat; i.e., arms, shoulders, hand, and neck. Even among participants who experienced supervised training (and performed squats several times a week), some of them did not consciously train their gluteals; instead, they only perceived training in the upper arms and shoulders (Figure 5). Comparatively, only 30\% of participants without regular exercise habits perceived training of the gluteal region when doing squats (Oshita et al., 2014). This suggests that appropriate supervision is of even greater importance in strength-training beginners who do not regularly exercise. Furthermore, about $10 \%$ of the EXP-group did not know that the knee extensors are amongst the trained areas. As shown in Figure 5, the anterior thighs were not marked while the gluteals and posterior thighs were, implying that squats are perceived as greater hip extension exercises, like the "good-morning exercise (Contreras et al., 2013)." Since most exercises can be easily performed through observation, awareness of the importance of professional instructors may be reduced. Strength-training should be performed with the proper methods and understanding in order to maintain and promote muscle strength and mass, as well as improve the quality of life. The results of the present study showed evidence of the importance of strength-training under appropriate supervision.

Unfortunately, this study only examined the perception of trained body parts in squats; further studies are necessary to consider what movements are actually performed. In addition, we only focused on university students, limiting other population samples. As for experience with supervised training, the question of whether one was a professional or expert trainer was up to the participants' subjective judgment. The level of these supervisors' knowledge or expertise is not certain. The Japan Sports Association (2014) conducted a survey among the teachers in charge of sports club activities, to examine their level of awareness about the qualifications of a coach in the association. They reported that $61 \%$ of junior high school teachers and $48 \%$ of high school teachers were not aware of these qualifications, suggesting that the level of awareness regarding these credentials was low. On the other hand, although various organizations such as the Japan Health Promotion \& Fitness Foundation, the Japan Association of Training Instructors and the National Strength \& Conditioning Association (to name a few), provide accreditation for qualifications and degrees related to exercise training, it is unclear whether they are generally recognized. Therefore, this study was investigated by the judgment of the strength training and sports experts on the subjectivity of the participants. Moreover, it suggests that even among qualified instructors, their expertise may not be guaranteed by these qualification systems (Nagamatsu and Morino, 1999). Furthermore, individuals with no prior credentials may have practiced strength-training from knowledge gained 
through their personal efforts. Further detailed studies need to be conducted in relation to qualifications and credentialing of supervisors, as well as on participants' own level of knowledge regarding weighttraining.

\section{Summary}

The present study investigated whether prior experience of supervised weight-training is related to the frequency of performing squats and the knowledge of squatting exercises among university students. More than half of the participants who exercised regularly had never experienced weight-training under appropriate supervision. Approximately $50 \%$ performed squats periodically, even in the absence of supervised weight-training. We found that participants with no experience in weight-training under supervision made significantly fewer attempts to consciously train their gluteal and knee flexor muscles during squats, compared with those with experience. In fact, approximately $50 \%$ of the former did not consciously train their gluteal muscles during squats at all. These results suggest that although the students performed squatting exercises periodically, those without supervised weight-training may not have properly understood the exercise method. Therefore, to enhance the benefits of training, people should be shown the correct method of performing these exercises and given the appropriate supervision.

\section{Note}

*1 A questionnaire survey carried out by the American College of Sports Medicine on people around the world working in the fitness industry, regarding what fitness-related trend they thought would be prevalent in the following year. There were 3,403 respondents for the 2014 survey (Thompson, 2014).

\section{References}

Aruga, S. (2009). 3-1 筋カトレーニングの実際 [Strength training]. In Japan Association of Training Instructors (ed.), トレーニング指導者テキスト実践編 [Practical textbook for JATI's training instructors] (pp. 122-139). Tokyo: Taishukan Publishing. (in Japanese)

Caterisano, A., Moss, R. F., Pellinger, T. K., Woodruff, K., Lewis, V. C., Booth, W., and Khadra, T. (2002). The effect of back squat depth on the EMG activity of 4 superficial hip and thigh muscles. J. Strength Cond. Res., 16: 428-432.

Chiu, L. Z. F. (2009). Sitting back in the squat. Strength Cond. J., 31: 25-27.

Chiu, L. Z. F. and Burkhardt, E. (2011). A teaching progression for Squatting Exercises. Strength Cond. J., 33: 46-54.

Contreras, B. M., Cronin, J. B., Schoenfeld B. J., Nates, R. J., and Sonmez G. T. (2013). Are all hip extension exercises created equal?. Strength Cond. J., 35: 17-22.

Earle, R. W. and Baechle, T. R. (2010). Chapter 14 Resistance training and spotting techniques. In T. R. Baechle \& R. W. Earle (eds.), NSCA 決定版 ストレングストレーニング \& コ ンディショニング (H. Kanehisa and J. Okada Trans.) (pp. 357-411). Tokyo: Book House HD. (Original work "Essentials of strength training and conditioning" published 2008).

Escamilla, R. F., Fleisig, G. S., Zheng, N., Barrentine, S. W., Wilk, K. E., and Andrews, J. R. (1998). Biomechanics of the knee during closed kinetic chain and open kinetic chain exercises. Med. Sci. Sports Exerc., 30: 556-569.

Fry, A. C., Smith, J. C., and Schilling, B. K. (2003). Effect of knee position on hip and knee torques during the barbell squat. J. Strength Cond. Res., 17: 629-633.

Fukui, T. (2006). 姿勢制御について [Posture control]. Rigaku ryouhouu: Rinshou Kyouiku Kenkyuu, 13: 2-6. (in Japanese)

Ishii, N. (2009). 9-7 動的レジスタンストレーニング [Dynamic resistance training]. In Japan Health Promotion \& Fitness Foundation (ed.), 健康運動指導士養成講習会テキスト(下) [Textbook of training workshop for health fitness programmer (Second volume)] (pp. 1015-1032). Tokyo: Shakai Hoken Kenkyuujo. (in Japanese)

Japan Sports Association (2014). 学校運動部活動指導者の実態 に関する調査報告書 [Report for the survey on instructor of extracurricular activities]. Tokyo: Japan Sports Association. (in Japanese)

Kouda, T. (1994). 筋カトレーニングについて [Strength training]. J. Exerc. Physiol., 9: 131-138. (in Japanese)

Manabe, Y., Yokozawa, T., and Ogata, M. (2003). スクワット の挙上重量変化が股関節と膝関節まわりの筋の活動および 関節卜ルクに与える影響 [Effect of load variation on lower muscle activity and joint torque during parallel squats]. Jpn. J. Phys. Fitness Sports Med., 52: 89-97. (in Japanese)

Manabe, Y., Yokozawa, T., and Ogata, M. (2004). 動作形態の 異なるスクワットが股関節と膝関節まわりの筋の活動およ び関節トルクに与える影響 [Effect of movement variation on lower limb muscle activity and joint torque during squat]. Jpn. J. Phys. Fitness Sports Med., 53: 321-336. (in Japanese)

McBride, J. M., Blow, D., Kirby, T. J., Haines, T. L., Dayne, A. M., and Triplett, N. T. (2009). Relationship between maximal squat strength and five, ten, and forty yard sprint times. J. Strength Cond. Res., 23: 1633-1636.

McCaw, S. T. and Melrose, D. R. (1999). Stance width and bar load effects on leg muscle activity during the parallel squat. Med. Sci. Sports Exerc., 31: 428-436.

Ministry of Health, Labor and Welfare of Japan (2014). 平成24 年度 国民健康·栄養調査報告 [2012 National Health and Nutrition Survey results]. Ministry of Health, Labor and Welfare of Japan. (in Japanese)

Miura, T. and Oda, Y. (2001). スクワット姿勢を制限する膝関 節屈曲に関する研究 [Knee flexibility as discriminators of foot contact during the squat exercise]. Essays Stud. Members Fac. Lett., 50: 53-71. (in Japanese)

Nagamatsu, M. and Morino, S. (1999). 社会体育指導者資格に 対するインストラクターの認知次元に関する研究: A フィ ットネス運営会社に勤務するインストラクターの事例から [A study on the leader's certification system for sport and fitness: Recognizable dimension about the certificate leader by professional instructors in a fitness club]. J. Jpn. Soc. Sports Ind., 9: 25-35. (in Japanese)

Nakamura, K. (2008). A "super-aged" society and the "locomotive syndrome". J. Orthop. Sci., 13: 1-2. 
Nakamura，K. (2012). ロコモティブシンドローム[運動器症 候群] [Locomotive syndrome]. Jpn. J. Geriatr., 49: 393-401. (in Japanese)

National Strength \& Conditioning Association (1991). N.S.C.A. position paper: The squat exercise in athletic conditioning: A position statement and review of the literature. Natl. Strength Cond. Assoc. J., 13: 51-58.

Ogasawara，I. (2013). スクワット動作の見方とそこからの発 展的トレーニング [Checkpoints of squatting movement and applied for actual training]. Sports Med., 155: 15-20.

Oshita, K., Yamaguchi, K., Oyama, Y., Hagiwara, G., and Funatsu，K. (2014). 大学生の運動習慣とスクワットに関す る認識について [Relationship between exercise habits and knowledge of squat exercise in university students]. Jpn. J. Physiol. Anthropol., 19: 239-245. (in Japanese)

Teraoka, E. and Matsumoto T. (2015). 中学校運動部活動にお ける教師の指導実態に関する研究 [Current status of coaching in club activities at Japanese junior high schools]. Jpn. J. Phys. Educ. Health Sport Sci., 60: 315-325. (in Japanese)

Thompson, W. R. (2011). Worldwide Survey of Fitness Trends for 2012. ACSM's Health Fit. J., 15: 9-18.

Thompson, W. R. (2012). Worldwide Survey of Fitness Trends for 2013. ACSM's Health Fit. J., 16: 8-17.

Thompson, W. R. (2013). Worldwide Survey of Fitness Trends for 2014. ACSM's Health Fit. J., 17: 10-20.

Thompson, W. R. (2014). Worldwide Survey of Fitness Trends for 2015. ACSM's Health Fit. J., 18: 8-17.

Wisløff, U., Castagna, C., Helgerud, J., Jones, R., and Hoff, J. (2004). Strong correlation of maximal squat strength with sprint performance and vertical jump height in elite soccer players. Br. J. Sports Med., 38: 285-288.

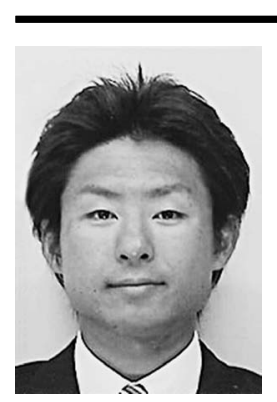

Name:

Kazushige Oshita

Affiliation:

Department of Sport Science, Kyushu Kyoritsu University

Address:

1-8, Jiyugaoka, Yahatanishi, Kitakyushu, Fukuoka, 807-8585 JAPAN

\section{Brief Biographical History:}

2008-2011 Doctoral Program in Graduate School of Human Development and Environment, Kobe University

2009-2011 Research Fellow of the Japan Society for the Promotion of Science

2011 Received Ph.D. at Kobe University

2011-present Research Associate (2011-2012), Assistant Professor (2012-2015), Senior Lecturer (2015-present), Department of Sport Science, Kyushu Kyoritsu University

Main Works:

- Oshita, K. and Yano, S. (2016) Effect and immediate aftereffect of lightly gripping the cane on postural sway. J. Physiol. Anthropol., 35: 14.

- Oshita, K. and Yano, S. (2013) Effects of light finger touch to the upper legs on postural sway and muscle activity during quiet standing. Conf. Proc. IEEE Eng. Med. Biol. Soc. 2013: 7459-7462.

- Oshita, K. and Yano, S. (2010) Asymmetry of force fluctuation in knee extension. Int. J. Sports Med. 31: 342-346.

Membership in Learned Societies:

- Japanese Society of Physical Fitness and Sports Medicine

- Japan Society of Physiological Anthropology

- Japanese Society for Medical and Biological Engineering 